\title{
Associations Between Elemental Constituents of Fine Particulate Matter and Subclinical Atherosclerosis in Adolescents and Young Adults
}

Szu-Ying Chen

E-Da Hospital/I-Shou University

Charlene Wu

National Taiwan University

Chang-Fu Wu

National Taiwan University

Chang-Chuan Chan

National Taiwan University

Jing-Shiang Hwang

Academia Sinica

Ta-Chen Su ( $\boldsymbol{\nabla}$ tachensu@gmail.com )

National Taiwan University Hospital https://orcid.org/0000-0001-7523-7166

\section{Research}

Keywords: particulate matter, elemental constituents, carotid intima-media thickness, atherosclerosis, young population

Posted Date: June 2nd, 2021

DOl: https://doi.org/10.21203/rs.3.rs-560265/v1

License: (c) (i) This work is licensed under a Creative Commons Attribution 4.0 International License. Read Full License 


\section{Abstract}

\section{Background}

Existing studies have demonstrated the relationships between particulate matter (PM) exposure and subclinical atherosclerosis; however, whether PM and its elemental constituents predispose to atherosclerosis remains unclear in adolescents and young adults. This cross-sectional study included 789 subjects between the ages of 12 to 30 years who lived in Taipei metropolis since childhood. Health examination and carotid intima-media thickness (CIMT) measurements were performed between 2006 and 2008. Land use regression (LUR) model was used to estimate participants' one-year exposure to fine particulate matter $\left(\mathrm{PM}_{2.5}\right)$ and eight elemental constituents, i.e., silicon ( $\left.\mathrm{Si}\right)$, sulfur (S), titanium ( $\mathrm{Ti}$ ), manganese $(\mathrm{Mn})$, iron $(\mathrm{Fe})$, nickel $(\mathrm{Ni})$, copper $(\mathrm{Cu})$, and zinc $(\mathrm{Zn})$. The associations between percent differences in CIMT at common carotid artery (CCA) segments and air pollutants were analyzed.

Results

An interquartile range increment of $\mathrm{PM}_{2.5}\left(4.5 \mu \mathrm{g} / \mathrm{m}^{3}\right), \mathrm{Fe}\left(34.7 \mathrm{ng} / \mathrm{m}^{3}\right)$, and $\mathrm{Zn}\left(20.7 \mathrm{ng} / \mathrm{m}^{3}\right)$ are associated with $0.77 \%$ (95\% confidence interval; $95 \% \mathrm{Cl}$ : 0.05 to 1.50$), 0.83 \%(0.01$ to 1.65$)$, and $1.22 \%$ ( 0.35 to 2.10$)$ higher for combined CIMT, respectively; while $\mathrm{Mn}\left(2.0 \mathrm{ng} / \mathrm{m}^{3}\right)$ exposure is associated with $0.31 \%$ (0.01 to 0.60 ) higher for right CIMT. Stratified analyses show $\mathrm{PM}_{2.5}$ and elemental constituents, especially Zn, are associated with CIMT among subjects who are 18 years or older, females, lower household income, non-smokers, normal weight, non-hypertensive, non-hyperglycemic, or nonhypercholesterolemic.

\section{Conclusions}

Long-term exposures to $\mathrm{PM}_{2.5}$ and elemental constituents mainly originating from traffic and industry operations are associated with subclinical atherosclerosis in young population. Individual characteristics, health behaviors, and biometric measures, may modify air pollution-related subclinical atherosclerosis.

\section{Background}

Particulate air pollution has been demonstrated a novel environmental risk factor of cardiovascular disease (CVD) in the last decade [1], and the acceleration of atherosclerosis has been proposed as one of important biological pathway linking relationships between CVD and long-term exposed to particulate matter (PM) [1, 2]. Chronic exposure to PM have been evident to associate with a variety of indicators of atherosclerosis, including ankle-brachial index, carotid intima-media thickness (CIMT), or coronary aortic calcification (CAC) among middle- or old-age population [3-15]. However, the relationships between particulate air pollutants and atherosclerosis in young population are equivocal in previous studies. Although two epidemiological studies on adolescents or young adults showed gaseous pollutants, i.e. $\mathrm{NO}_{2}$ and $\mathrm{O}_{3}$, were associated subclinical atherosclerosis [16, 17], PM exposure was not observed to associate with a variety of atherosclerosis indicators, including pulse wave velocity, augmentation index, 
or CIMT [16, 17], except higher augmentation index observed with exposed to $\mathrm{PM}_{2.5}$ among young females or non-smokers by subgroup analyses [17]. An epidemiological study conducted in Netherland children demonstrated $\mathrm{PM}_{2.5}, \mathrm{NO}_{2}$, and nitrogen oxides $\left(\mathrm{NO}_{\mathrm{X}}\right)$ exposures are associated with decreased carotid artery distensibility, but not CIMT [18]. Children residing $<100$ meters from heavily trafficked road were reported to have higher CIMT measurements compared with those who living $\geq 200$ meters away, suggesting urban traffic exposures promotes atherosclerotic process in children [19]. The heterogeneity as abovementioned may indicate more surveys on concentrations and source-specific compositions of air pollutants and the mediation of individual demographics are necessary while evaluating atherosclerotic effects of air pollution in young population. Therefore, we designed a cross-sectional study consisted of adolescents and young adults living in Taipei metropolis and applied land use regression model (LUR) to estimate individual exposures to fine particulate matter $\left(\mathrm{PM}_{2.5}\right)$ and eight elemental constituents. The associations of one-year exposures to $\mathrm{PM}_{2.5}$ and elemental constituents with CIMT values, and the potential mediation of individual characteristics were also examined.

\section{Methods}

\section{Study Subjects}

In this cross-sectional study, we included 789 subjects who aged 12-30 years and lived in Taipei metropolis. The study subjects were selected from the YOung TAiwanese (YOTA) Cohort Study, a nationwide urine screening program which was conducted among 103,756 school-age children between the ages of 6 to 18 from 1992 to 2000. Detailed information on this program is provided in previous study [20]. After excluding 38,118 subjects with unreliable or missing data and 96,659 subjects who did not live in Taipei metropolis, 7160 subjects were invited for the follow-up health examination via telephone or mail during 2006ه2008. A total of 789 subjects completed the follow-up health examination. The participants in this study contained higher proportion of females, the majority of whom were older in age and possess higher systolic and diastolic blood pressures (BP), serum cholesterol levels compared to the 6,371 subjects who were lost to follow-up (Supplemental Table 1, see additional file 1). All of the participants and their parents signed informed consent documents upon enrollment in the study. The study was approved by the Ethics Committee of National Taiwan University Hospital (NTUH).

\section{Health Data}

The follow-up health examination was conducted in NTUH from 2006 to 2008 and consisted of a clinician interview, a structured and self-reported questionnaire, venous blood biochemical analysis, as well as BP and CIMT measurements. The clinician interview and questionnaire provided information of individual characteristics, such as age, sex, household income [New Taiwan Dollar (NTD) per month], smoking, and alcohol consumption. Body mass index (BMI) was calculated as body weight (kg) divided by the square of body height (in meters). Here, overweight is defined by $B M I \geq 25 \mathrm{~kg} / \mathrm{m}^{2}$. 
The venous blood sample was collected from an antecubital vein after a fasting period of 10-14 hours. The blood glucose, serum total cholesterol, triglyceride, high- and low-density lipoprotein cholesterol were analyzed using an auto-analyzer (Hitachi 7250 Special; Hitachi, Tokyo, Japan) in central lab at NTUH. Hyperglycemia is defined as fasting blood glucose level $\geq 100 \mathrm{mg} / \mathrm{dL}$, and hypercholesterolemia is defined as total cholesterol level $\geq 200 \mathrm{mg} / \mathrm{dL}$.

BP values were measured using a mercury sphygmomanometer in a standardized fashion, with the cuffsize adjusted to the circumference of the arm. The mean of two measurements obtained after 5-10 minutes of rest in the seated position with the legs uncrossed in a quiet room was used as the BP measurement. If the difference in the two BP measurements was greater than $10 \mathrm{~mm} \mathrm{Hg}$, a third BP measurement was obtained, and the average of the lowest two measured BP values was selected as the subject's BP. Hypertensive status was determined by participant either had self-reported physiciandiagnosed hypertension and used anti-hypertensive medication or had measured BP values $\geq 140 \mathrm{mmHg}$ for systolic BP or $\geq 90 \mathrm{mmHg}$ for diastolic BP.

\section{CIMT Measurement}

CIMT, defined as the distance from the front edge of the first echogenic line (lumen-intima interface) to the front edge of the second echogenic line (media-adventitia interface) in the far wall of the vessel, was measured by an experienced technician using high-resolution B-mode ultrasonography (GE Vivid ultrasound system, Horten, Norway) equipped with a 3.5- to 10-MHz real-time B-mode scanner. The values of the CIMT at the common carotid artery (CCA) proximal to the carotid bifurcation were measured bilaterally. All scans were recorded on a digitalized memory system in Digital Imaging and Communications in Medicine (DICOM) format for subsequent offline analysis. The digitized M-mode was later analyzed off-line using a computer program, in which each image was recalled with magnification and the CIMT between two successive $\mathrm{R}$ waves was measured by automated analyzing software provided by the manufacturer. The details in the protocol for CIMT measurements has been described in previous studies [20]. In this study, we used averaging measurements of CIMT values at left CCA (LCCA), right CCA (RCCA), and means of bilateral CCA (combined CCA) as health outcomes. To ensure the reliability of repeat measurements, a technician conducted a second reading for randomly selected 30 subjects two weeks later. The reliability of CCA measurement had excellent intra-observer correlation coefficients of $98.8 \%$ for RCCA, and $98.5 \%$ for LCCA [21].

\section{Air Pollution Exposure Assessment.}

We used land use regression (LUR) model developed by Ho et al. (2015) to estimate individual's annual average exposure concentrations of $\mathrm{PM}_{2.5}$ and eight elemental constituents, i.e., silicon (Si), sulfur (S), titanium (Ti), manganese (Mn), iron (Fe), nickel (Ni), copper (Cu), and zinc ( $\mathrm{Zn})$ [22]. This modeling approach was derived from projects of ESCAPE (European Study of Cohorts for Air Pollution Effects) [23]. In brief, $\mathrm{PM}_{2.5}$ samples were collected at 20 low-level sites (first to third floors), five mid-level sites (fourth to sixth floors), and five high-level sites (seventh to ninth floors) from Taipei metropolis, Taiwan, between 
January and October of 2010. Each $\mathrm{PM}_{2.5}$ sampling site was measured twice with a five-month interval, and each measurement was collected for two-week period with a Harvard impactor (Air Diagnostics and Engineering Inc., Harrison, ME, USA). The eight elemental constituents were identified and quantitatively determined using energy-dispersive X-ray fluorescence spectrometry at the National Taiwan University [24].

ArcGIS (version 10.1; ESRI) was used to obtain geographic information system information for land use data (residential land, industry, port, urban green, and natural space) and traffic information (total length of major roads and road segments, the distance to the nearest major road and the nearest road). Predictor variables with multiple buffer sizes $(100,300,500,1000$, and $5000 \mathrm{~m}$ for land use data; 25, 50, $100,300,500$, and $1000 \mathrm{~m}$ for traffic data) were applied to estimate the influence of spatial variability on $\mathrm{PM}_{2.5}$ elemental constituent exposures. Supervised forward stepwise multiple regression to derive the final LUR models. We summarized the equations and parameters in Supplemental Table 2 (Additional file 2). Potassium was excluded from this study because its associated predictor variables all presented nonsignificant effects in the LUR model. Individual's annual exposure estimates which vary by more than three standard deviations (SD) were removed as outliers.

\section{Statistical analyses.}

Multiple linear regressions were applied to assess the associations of LCCA, RCCA, and combined CCA with an interquartile range (IQR) increase in annual averages of $\mathrm{PM}_{2.5}$ and eight elemental constituents. The following covariates were adjusted in the main model: age, sex, household income, smoking status, BMI, systolic BP, fasting blood glucose, and total cholesterol. In the extended model, we further adjusted for individual's urinary cotinine levels in addition to the selected covariates in the main model to consider the possible effect of environmental smoke. Stratified analyses were performed to examine whether associations between CIMT values and air pollutants are modified by individual characteristics, including age ( $<18$ years vs. $\geq 18$ years), sex, smoking status (non-smoking vs. current smoking), household income (<NTD 50,000/month vs. $\geq$ NTD 50,000/month), overweightness (BMI $<25 \mathrm{~kg} / \mathrm{m}^{2} \mathrm{vs}$. BMI $\geq 25$ $\mathrm{kg} / \mathrm{m}^{2}$ ), hypertension, hyperglycemia (fasting glucose $<100 \mathrm{mg} / \mathrm{dL}$ vs. fasting glucose $\geq 100 \mathrm{mg} / \mathrm{dL}$ ), and hypercholesterolemia (total cholesterol $<200 \mathrm{mg} / \mathrm{dL}$ vs. total cholesterol $\geq 200 \mathrm{mg} / \mathrm{dL}$ ). The estimates are presented by percent differences and $95 \%$ confidence intervals (Cls) of CIMT values for an IQR increment in each of air pollutant. The analyses were performed using SAS software (version 9.1.3; SAS Institute Inc., Cary, NC).

\section{Results}

The average age of study participants in the follow-up study was $21.3 \pm 3.3$ years, and females account for $60.3 \%$ of all 789 individuals. The means (SD) of CIMT values at LCCA, RCCA, and combined CCA are all $0.45 \pm 0.06 \mathrm{~mm}$. Table 1 details the distribution of study subjects and CIMT measurements stratified by individual characteristics. The CIMT values at LCCA RCCA, and combined CCA are higher in males, 
current smokers, or subjects who are overweight, hypertensive, hyperglycemic, or hypercholesterolemic. The CIMT values are not different between age and household income stratum.

Table 2 shows the one-year average exposure concentrations of $\mathrm{PM}_{2.5}$ and eight elemental constituents for study subjects. After removing 10 subjects whose estimated annual average concentrations of $\mathrm{PM}_{2.5}$ exceed more than three SD, the mean (SD) values of annual average concentrations of $\mathrm{PM}_{2.5}$ of 779 subjects ( $98.7 \%$ of all 789 participants) is $24.9 \pm 5.0 \mu \mathrm{g} / \mathrm{m}^{3}$, which exceed the National Ambient Air Quality Standards of Taiwan $\left(15 \mu \mathrm{g} / \mathrm{m}^{3}\right)$. The annual concentrations of $\mathrm{Mn}$ and $\mathrm{Zn}$ are averaged by 756 and 755 subjects after further removing 23 and 24 outlier values, respectively. Among the eight constituents, the highest annual average concentration is $2180.6 \mathrm{ng} / \mathrm{m}^{3}$ for $S$ and the lowest annual average is $6.5 \mathrm{ng} / \mathrm{m}^{3}$ for Ni. For eight elemental constituents, Si is highly correlated to S (Pearson's correlation coefficient, $r=0.827), \mathrm{Mn}$ is highly correlated to $\mathrm{Zn}(\mathrm{r}=0.577)$, and $\mathrm{Fe}, \mathrm{Cu}$, and $\mathrm{Zn}$ are strongly correlated with each other (Supplemental Table 3, see additional file 3).

Table 3 shows the percent difference of the mean values CIMT at LCCA, RCCA, and combined CCA in association with one-year exposure to $\mathrm{PM}_{2.5}$ and eight elemental components. After adjusting for individual covariates, RCCA values are positively associated with one-year exposures to $\mathrm{PM}_{2.5}, \mathrm{Mn}$, and $\mathrm{Zn}$, and are marginally higher with exposed to Fe. LCCA IMT values are observed to be associated with one-year exposures to Fe and $\mathrm{Zn}$, and are marginally associated with one year-exposure to $\mathrm{PM}_{2.5}$. Combined CCA IMT values are observed to be $0.77 \%(95 \% \mathrm{Cl}: 0.05,1.50), 0.27 \%$ (95\% Cl: $0.00,0.53)$, $0.83 \%$ (95\% Cl: $0.01,1.65)$, and $1.22 \%(95 \% \mathrm{Cl}: 0.35,2.10)$ higher with an IQR increment for $\mathrm{PM}_{2.5}(4.5$ $\left.\mu \mathrm{g} / \mathrm{m}^{3}\right), \mathrm{Mn}\left(2.0 \mathrm{ng} / \mathrm{m}^{3}\right), \mathrm{Fe}\left(34.7 \mathrm{ng} / \mathrm{m}^{3}\right)$, and $\mathrm{Zn}\left(20.7 \mathrm{ng} / \mathrm{m}^{3}\right)$, respectively. To account for the possible effect of environmental smoke, the extended model still shows positive associations of exposures to $\mathrm{PM}_{2.5}, \mathrm{Mn}$, Fe, and Zn with CIMT values at RCCA, LCCA, and combined CCA after further adjustment for individual's urinary cotinine in addition to covariates selected in the main model.

Fig 1 illustrated percent differences (95\% Cls) of combined CCA IMT in association with an IQR increment of $\mathrm{PM}_{2.5}, \mathrm{Mn}, \mathrm{Fe}$, and $\mathrm{Zn}$ stratified by individual characteristics and comorbidities. We observed stronger associations between combined CCA values and $\mathrm{PM}_{2.5}$ among subjects who are 18 years or older, females, possessed lower household income (< NTD 50,000/month), and are non-hypertensive compared with the counterparts of these subgroups with significant interaction. The $p$-values for interaction of age, sex, household income, and hypertension between $\mathrm{PM}_{2.5}$ and combined CCA IMT are 0.022, 0.023, 0.016, and 0.021 , respectively. Participants who are non-smokers, normal weight, non-hyperglycemic, and nonhypercholesterolemic are observed to have marginal associations between $\mathrm{PM}_{2.5}$ and combined CCA IMT, but not in the counterparts of these subgroups. For elemental constituents, an IQR increment for $\mathrm{Zn}$ are $1.29 \%$ (95\% Cl: $0.34,2.24), 1.60 \%$ (95\% Cl: $0.53,2.66), 2.53 \%$ (95\% Cl: 1.01, 4.04), 1.22\% (95\% Cl: 0.29 , 2.15), $1.11 \%$ (95\% Cl: $0.19,2.04), 1.28 \%$ (95\% Cl: $0.37,2.18), 1.13 \%$ (95\% Cl: $0.25,2.01)$, and $1.31 \%$ (95\% Cl: $0.37,2.25)$ higher for combined CCA IMT values among subjects who are 18 years or older, females, lower household income, non-smokers, normal weight, non-hypertensive, non-hyperglycemic, or non- 
hypercholesterolemic, but not in the counterparts of these subgroups. The results of stratified analyses for associations of combined CIMT with $\mathrm{Mn}$ and Fe exposures are similar to those for $\mathrm{PM}_{2.5}$ exposures.

\section{Discussion}

This is the first study to demonstrate chronic exposures to $\mathrm{PM}_{2.5}$ and transition metal components, including $\mathrm{Mn}, \mathrm{Fe}$, and $\mathrm{Zn}$, are associated with subclinical atherosclerosis in young population. Although previous studies reported on the associations between traffic proximity, $\mathrm{O}_{3}$, or $\mathrm{NO}_{X}$ exposures and CIMT in young population, they failed to demonstrate PM are associated with CIMT $[16,17]$. There are several strengths in ours study findings. First, our exposure assessment of air pollutants and elemental constituents were conducted with LUR model which accounted for the effects of vertical distribution for high-rise buildings in urban area, thus minimizing exposure measurement error. Second, our study design largely ruled out the exposure misclassification from relocation, since our participants were invited for follow-up health examination in 2006-2008 according to the address left at the first enrollment in the YOTA study from 1992 to 2000 . Third, all participants are young population of age 12-30 years, with less individual cardiovascular risk factors that may highlight the atherosclerotic effect of air pollutants. Although the point estimates of $\mathrm{PM}_{2.5}$ and transition metals on CIMT in this study were incremental, the results are still believed to add new insight on public health impact, even young population are less prevalent in cardiovascular comorbidities than older adults.

Though several studies have demonstrated associations between PM and CIMT in middle- or old-age population $[3,4,13,14,25]$, our study first demonstrates the positive associations between $\mathrm{PM}_{2.5}$ and CIMT in young population. The individuals in this study exposed high annual exposure concentrations of $\mathrm{PM}_{2.5}\left(24.9 \mu \mathrm{g} / \mathrm{m}^{3}\right)$, which is almost twice as high compared to those reported in published studies in western countries, may contribute to this particular finding. Nevertheless, the point estimate of percent difference in CIMT with $\mathrm{PM}_{2.5}$ exposure (0.77\% with exposed to $4.5 \mu \mathrm{g} / \mathrm{m}^{3}$ of $\mathrm{PM}_{2.5}$ ) in this study is lower than a previous meta-analysis that showed a $5 \mu \mathrm{g} / \mathrm{m}^{3}$ increment of long-term exposure to $\mathrm{PM}_{2.5}$ is associated with $1.66 \%$ change in CIMT [26]. The heterogenous findings between differernt age group may be attributable to that CIMT is chronic process in structural change and take longer time to demonstrate the measureable differences. Subroup analysis of this stuty showed significant associations between CIMT and $\mathrm{PM}_{2.5}$ only among young adults but not adolescents also support abovementioned hypothesis. Breton et al. (2012) demonstrated the effect estimate of CIMT of young adults are stonger among sbujects with cumulative $\mathrm{O}_{3}$ exposure since early childhood than those exposured in later life [16].

In addition to $\mathrm{PM}_{2.5}$, we further demonstrate long-term exposure to certain transition metals of $\mathrm{PM}_{2.5}$, namely $\mathrm{Mn}, \mathrm{Fe}$, and Zn, are associated with higher CIMT values. Epidemiological studies have demonstrated specific human activities, such as residing traffic proximity and cooking fuels, are associated with increased CIMT measures $[11,12,27,28]$. Certain source-specific components of PM, including organic carbon, elemental carbon, black carbon, and $S$ were reported to associate with increased CIMT values in elderly population [12, 28-31]. $\mathrm{PM}_{2.5 a b s o r b a n c e}$ exposure was associated to 
decreased carotid artery distensibility in young children [18]. Several studies also demonstrated exposures to elemental components of $\mathrm{PM}_{2.5}$ contribute to other adverse cardiovascular effects related to atherosclerosis. Bilenko et al. (2015) demonstrated that $\mathrm{PM}_{10}$ elements, including $\mathrm{Fe}, \mathrm{K}$, and $\mathrm{Si}$ associated with higher diastolic $\mathrm{BP}$ values in children [32]. $\mathrm{PM}_{2.5}$ metal composition, including $\mathrm{Ni}$, $\mathrm{Fe}$, and vanadium, were also reported to associate with higher BP values in young adults or elderly persons [33, 34]. Long-term exposures to $\mathrm{Cu}, \mathrm{Fe}$, and $\mathrm{Zn}$, the transition metals of PM, may be associated with higher inflammatory biomarkers [35]. A panel study of 17 mail carriers showed that metal compositions of $\mathrm{PM}_{2.5-1.0}$, including sodium, magnesium, calcium, strontium, manganese, and cadmium, significantly increased the cardio-ankle vascular index, a surrogate marker of arterial stiffness [36]. These elements are emitted from multiple sources, such as $\mathrm{Mn}, \mathrm{Cu}, \mathrm{Fe}$, and $\mathrm{Zn}$ from brake linings and tires; Si and Ti from road dust suspended by automobiles and wind; $\mathrm{Ni}$ and $\mathrm{S}$ from industrial or fossil fuel combustion [37, 38]. According to the regression coefficients, the strongest influence in LUR models for Fe and $\mathrm{Zn}$ are mainly attributed to traffic- or industry-related covariates, while Zn may also be partially emitted from population variables, such as cooking activities. $\mathrm{Mn}$ is primarily generated from the port activities, and partially from traffic, and industry operations. Because ship decommissioning activity does not exist in the buffers around sampling sites, Ho et al. (2015) speculated Mn possibly emitted by abrasive wear activities from ship movement in wharfs of Taipei metropolis [22]. Our study results suggest sourcespecific $\mathrm{PM}_{2.5}$, primary from vehicular or industrial emissions, contribute to extra risk of subclinical atherosclerosis in young population.

The stratified analyses show that associations of combined CCA IMT values with $\mathrm{PM}_{2.5}, \mathrm{Mn}, \mathrm{Fe}$, or $\mathrm{Zn}$ are stronger in subjects who are females or lower household incomes than those with contrary stratum, which may suggest females or subjects with lower socioeconomic (SES) status are more vulnerable to exposure of air pollution, resulting in the acceleration of subclinical atherosclerosis. Existing research support our finding that carotid arterial wall thickness is more pronounced in females exposed to $\mathrm{PM}_{2.5}$ $[8,25,39]$. This observed vulnerability among females could be due to females having smaller airways, resulting in enhanced deposition of fine particles. More frequent exposures to cooking fuel among women may further contribute to the stronger associations of $\mathrm{PM}_{2.5}$ exposures with Taiwanese females. The epidemiological study in India showing associations between use of unvented stove and higher CIMT values, especially in women [11], further support our findings. The mediation effect of SES on relationships between air pollution and cardiovascular health still remains inconclusive [40]; however, several studies reported lower individual or neighborhood SES status may enhance the air pollutionrelated cardiovascular risk. Higher risk estimates of cardiovascular events with exposure to $\mathrm{PM}_{2.5}$ were observed among participants living in low-SES neighborhoods [41]. Dragano et al. (2009) observed that women in the lowest income stratum have a significantly higher level of coronary artery calcification (CAC) associated with pollution exposure compared to women in the highest income stratum [42]. Diez Roux et al. (2004) reported that low SES status also suffer from worse health outcomes resulting from psychosocial stress, which may mediate the effect of air pollution-related atherosclerosis [43]. The higher air pollution and noise exposures in subjects with lower SES due to their residency proximity to traffic- or 
industrial-area may also contribute to the mediation between air pollution and subclinical atherosclerosis [42].

Stratified analyses of this study further demonstrate the vulnerability to air pollution in low cardiovascular risk subjects of non-smoking, normal weight, non-hypertensive, non-hyperglycemic, or nonhypercholesterolemic young population. Some other studies also agree with our findings. Kauffman et al. (2016) reported that the progression of coronary artery calcification with exposures to $\mathrm{PM}_{2.5}$ and $\mathrm{NO}_{\mathrm{X}}$ might be greater in non-diabetic, non-obese, non-hypercholesterolemic subjects [8]. Epidemiological studies also reported that associations between PM and decreased renal function are stronger in nondiabetic subjects, which may share atherosclerotic change as the common pathophysiologic pathway $[44,45]$. Our previous study also observed that CIMT values are associated with perfluorinated chemicals in healthy young subgroups [21]. One possible explanation to the stronger effect of air pollution-related atherosclerosis in healthier young subjects is that the effect of air pollution on CIMT is weaker than the traditional cardiovascular risk factors such as obesity, smoking, hypertension, hyperglycemia, or hypercholesterolemia, which results in findings of insignificant air pollution-related atherosclerosis on subjects with unhealthy lifestyle or comorbidities. In other words, healthy young population must be more aware of air pollution-related atherogenic effect.

Several study limitations should be addressed. First, the lag time existed between health examination (performed during 2006-2008) and exposure concentration estimation (LUR developed in 2009-2010). The annual average concentrations of $\mathrm{PM}_{2.5}$ in Taipei metropolis during 2006-2010 slightly decreased in trend (46), which could result in underestimation of personal annual mean exposures and effect estimates. Second, the $\mathrm{R}^{2}$ validations for several elemental constituents, including $\mathrm{Si}, \mathrm{S}, \mathrm{Ti}, \mathrm{Ni}$, and $\mathrm{Zn}$, are less than 0.40 (Supplemental Table 2), which could possibly influence the accuracy of model prediction. Third, the results of stratified analyses may be biased under multiple comparisons, and insignificant findings among comorbid groups may be attributed to small sample size and wide confidence intervals. More studies are necessary to elucidate the population susceptibility of subclinical atherosclerosis to air pollution. Other possible unmeasured confounders are ambient or traffic noise, and endocrine disrupting chemicals such as perfluorinated compounds and phthalates, which have been shown to associate with atherosclerosis $[47,48]$.

\section{Conclusions}

This cross-sectional study supports the notion that not only $\mathrm{PM}_{2.5}$, but elemental components of $\mathrm{PM}_{2.5}$, i.e., $\mathrm{Mn}, \mathrm{Fe}$, and $\mathrm{Zn}$, play more important role on the process of subclinical atherosclerosis in young population. Individual characteristics, including age, sex, smoking status, SES, or healthy status may modify the effects of $\mathrm{PM}_{2.5}$ and elemental constituents on subclinical atherosclerosis. Future research which focus on the source-specific air pollution in young population, especially in the vulnerable subpopulation, are warranted. 


\section{Abbreviations}

BMI: body mass index; BP: blood pressure; CAC: coronary aortic calcification; CCA: common carotid artery; CIMT: carotid intima-media thickness; Cu: copper; Fe: iron; CVD: cardiovascular disease; LCCA: left common carotid artery; LUR: land use regression; Mn: manganese; NTD: New Taiwan Dollar; Ni: nickel; $\mathrm{NO}_{X}$ : nitrogen oxides; NTUH: National Taiwan University Hospital; PM: particulate matter; $\mathrm{PM}_{2.5}$ : fine particulate matter; RCCA: right common carotid artery; S: sulfur; Si: silicon; Ti: titanium; Zn: zinc.

\section{Declarations}

\section{Acknowledgements}

The authors would like to thank the $3^{\text {rd }}$ core laboratory of National Taiwan University Hospital for laboratory examination support.

\section{Authors' contributions}

Conceptualization: SYC and TCS. Data curation: TCS. Methodology: CFW and CCC. Formal analysis: SYC, TCS, and JSH. Writing-original draft: SYC and TCS. Writing-review \& editing: CW and TCS.

\section{Funding}

This research was funded by the National Health Research Institutes of Taiwan (NHRI-EX107-10629PI).

This work was partially supported by the collaborative project of E-Da Hospital and National Taiwan University Hospital (106-EDN11), and Innovation and Policy Center for Population Health and Sustainable Environment (Population Health Research Center, PHRC), College of Public Health, National Taiwan University from The Featured Areas Research Center Program within the framework of the Higher Education Sprout Project by the Ministry of Education (MOE) in Taiwan (NTU-107L9003).

\section{Availability of data and materials}

All the data that support the findings of this study are available on request from the corresponding author.

\section{Ethics approval and consent to participate}

All of the participants and their parents signed informed consent documents upon enrollment in the study. The study was approved by the Ethics Committee of National Taiwan University Hospital (NTUH).

\section{Consent for publication}

Not applicable.

\section{Competing interests}


The authors declare that they have no competing interests.

\section{References}

1. Brook RD, Rajagopalan S, Pope CA, 3rd, Brook JR, Bhatnagar A, Diez-Roux AV, et al. Particulate matter air pollution and cardiovascular disease: An update to the scientific statement from the American Heart Association. Circulation. 2010;121(21):2331-78.

2. Rajagopalan S, Al-Kindi SG, Brook RD. Air Pollution and Cardiovascular Disease: JACC State-of-theArt Review. Journal of the American College of Cardiology. 2018;72(17):2054-70.

3. Adar SD, Sheppard L, Vedal S, Polak JF, Sampson PD, Diez Roux AV, et al. Fine particulate air pollution and the progression of carotid intima-medial thickness: a prospective cohort study from the multi-ethnic study of atherosclerosis and air pollution. PLoS medicine. 2013;10(4):e1001430.

4. Bauer M, Moebus S, Mohlenkamp S, Dragano N, Nonnemacher M, Fuchsluger M, et al. Urban particulate matter air pollution is associated with subclinical atherosclerosis: results from the HNR (Heinz Nixdorf Recall) study. Journal of the American College of Cardiology. 2010;56(22):1803-8.

5. Diez Roux AV, Auchincloss AH, Franklin TG, Raghunathan T, Barr RG, Kaufman J, et al. Long-term exposure to ambient particulate matter and prevalence of subclinical atherosclerosis in the MultiEthnic Study of Atherosclerosis. American journal of epidemiology. 2008;167(6):667-75.

6. Duan C, Talbott E, Brooks M, Park SK, Broadwin R, Matthews K, et al. Five-year exposure to PM(2.5) and ozone and subclinical atherosclerosis in late midlife women: The Study of Women's Health Across the Nation. International journal of hygiene and environmental health. 2019;222(2):168-76.

7. Hennig F, Geisel MH, Kälsch H, Lucht S, Mahabadi AA, Moebus S, et al. Air Pollution and Progression of Atherosclerosis in Different Vessel Beds-Results from a Prospective Cohort Study in the Ruhr Area, Germany. Environmental health perspectives. 2020;128(10):107003.

8. Kaufman JD, Adar SD, Barr RG, Budoff M, Burke GL, Curl CL, et al. Association between air pollution and coronary artery calcification within six metropolitan areas in the USA (the Multi-Ethnic Study of Atherosclerosis and Air Pollution): a longitudinal cohort study. Lancet (London, England). 2016;388(10045):696-704.

9. Kunzli N, Jerrett M, Garcia-Esteban R, Basagana X, Beckermann B, Gilliland F, et al. Ambient air pollution and the progression of atherosclerosis in adults. PloS one. 2010;5(2):e9096.

10. Perez L, Wolf K, Hennig F, Penell J, Basagana X, Foraster M, et al. Air pollution and atherosclerosis: a cross-sectional analysis of four European cohort studies in the ESCAPE study. Environmental health perspectives. 2015;123(6):597-605.

11. Ranzani OT, Milà C, Sanchez M, Bhogadi S, Kulkarni B, Balakrishnan K, et al. Association between ambient and household air pollution with carotid intima-media thickness in peri-urban South India: CHAl-Project. Int J Epidemiol. 2020;49(1):69-79.

12. Rivera $M$, Basagana $X$, Aguilera I, Foraster $M$, Agis D, de Groot E, et al. Association between long-term exposure to traffic-related air pollution and subclinical atherosclerosis: the REGICOR study. 
Environmental health perspectives. 2013;121(2):223-30.

13. Su TC, Hwang JJ, Shen YC, Chan CC. Carotid Intima-Media Thickness and Long-Term Exposure to Traffic-Related Air Pollution in Middle-Aged Residents of Taiwan: A Cross-Sectional Study. Environmental health perspectives. 2015;123(8):773-8.

14. Tonne C, Yanosky JD, Beevers S, Wilkinson P, Kelly FJ. PM mass concentration and PM oxidative potential in relation to carotid intima-media thickness. Epidemiology (Cambridge, Mass). 2012;23(3):486-94.

15. Wang M, Hou ZH, Xu H, Liu Y, Budoff MJ, Szpiro AA, et al. Association of Estimated Long-term Exposure to Air Pollution and Traffic Proximity With a Marker for Coronary Atherosclerosis in a Nationwide Study in China. JAMA Netw Open. 2019;2(6):e196553.

16. Breton CV, Wang X, Mack WJ, Berhane K, Lopez M, Islam TS, et al. Childhood air pollutant exposure and carotid artery intima-media thickness in young adults. Circulation. 2012;126(13):1614-20.

17. Lenters V, Uiterwaal CS, Beelen R, Bots ML, Fischer P, Brunekreef B, et al. Long-term exposure to air pollution and vascular damage in young adults. Epidemiology (Cambridge, Mass). 2010;21(4):51220.

18. Ntarladima AM, Vaartjes I, Grobbee DE, Dijst M, Schmitz O, Uiterwaal C, et al. Relations between air pollution and vascular development in 5-year old children: a cross-sectional study in the Netherlands. Environmental health : a global access science source. 2019;18(1):50.

19. Armijos RX, Weigel MM, Myers OB, Li WW, Racines M, Berwick M. Residential exposure to urban traffic is associated with increased carotid intima-media thickness in children. Journal of environmental and public health. 2015;2015:713540.

20. Su TC, Liao CC, Chien KL, Hsu SH, Sung FC. An overweight or obese status in childhood predicts subclinical atherosclerosis and prehypertension/hypertension in young adults. Journal of atherosclerosis and thrombosis. 2014;21(11):1170-82.

21. Lin CY, Lin LY, Wen TW, Lien GW, Chien KL, Hsu SH, et al. Association between levels of serum perfluorooctane sulfate and carotid artery intima-media thickness in adolescents and young adults. International journal of cardiology. 2013;168(4):3309-16.

22. Ho CC, Chan CC, Cao CW, Lin HI, Lee JH, CF W. Land use regression modeling with vertical distribution measurements for fine particulate matter and elements in an urban area. Atmospheric Environment. 2015;104:256-63.

23. Eeftens M, Beelen R, de Hoogh K, Bellander T, Cesaroni G, Cirach M, et al. Development of Land Use Regression models for PM(2.5), PM(2.5) absorbance, PM(10) and PM(coarse) in 20 European study areas; results of the ESCAPE project. Environmental science \& technology. 2012;46(20):11195-205.

24. Wu CF, Lin HI, Ho CC, Yang TH, Chen CC, Chan CC. Modeling horizontal and vertical variation in intraurban exposure to PM2.5 concentrations and compositions. Environmental research. 2014;133:96-102.

25. Kunzli N, Jerrett M, Mack WJ, Beckerman B, LaBree L, Gilliland F, et al. Ambient air pollution and atherosclerosis in Los Angeles. Environmental health perspectives. 2005;113(2):201-6. 
26. Provost EB, Madhloum N, Int Panis L, De Boever P, Nawrot TS. Carotid intima-media thickness, a marker of subclinical atherosclerosis, and particulate air pollution exposure: the meta-analytical evidence. PloS one. 2015;10(5):e0127014.

27. Min M, Taneepanichskul N. Cooking fuels use and carotid intima-media thickness during early pregnancy of women in Myanmar. PloS one. 2020;15(7):e0236151.

28. Wang Y, Wellenius GA, Hickson DA, Gjelsvik A, Eaton CB, Wyatt SB. Residential Proximity to TrafficRelated Pollution and Atherosclerosis in 4 Vascular Beds Among African-American Adults: Results From the Jackson Heart Study. American journal of epidemiology. 2016;184(10):732-43.

29. Kim SY, Sheppard L, Kaufman JD, Bergen S, Szpiro AA, Larson TV, et al. Individual-level concentrations of fine particulate matter chemical components and subclinical atherosclerosis: a cross-sectional analysis based on 2 advanced exposure prediction models in the multi-ethnic study of atherosclerosis. American journal of epidemiology. 2014;180(7):718-28.

30. Sun M, Kaufman JD, Kim SY, Larson TV, Gould TR, Polak JF, et al. Particulate matter components and subclinical atherosclerosis: common approaches to estimating exposure in a Multi-Ethnic Study of Atherosclerosis cross-sectional study. Environmental health : a global access science source. 2013;12:39.

31. Wilker EH, Mittleman MA, Coull BA, Gryparis A, Bots ML, Schwartz J, et al. Long-term exposure to black carbon and carotid intima-media thickness: the normative aging study. Environmental health perspectives. 2013;121(9):1061-7.

32. Bilenko N, Brunekreef B, Beelen R, Eeftens M, de Hoogh K, Hoek G, et al. Associations between particulate matter composition and childhood blood pressure-The PIAMA study. Environment international. 2015;84:1-6.

33. Jacobs L, Buczynska A, Walgraeve C, Delcloo A, Potgieter-Vermaak S, Van Grieken R, et al. Acute changes in pulse pressure in relation to constituents of particulate air pollution in elderly persons. Environmental research. 2012;117:60-7.

34. Wu S, Deng F, Huang J, Wang H, Shima M, Wang X, et al. Blood pressure changes and chemical constituents of particulate air pollution: results from the healthy volunteer natural relocation (HVNR) study. Environmental health perspectives. 2013;121(1):66-72.

35. Hampel R, Peters A, Beelen R, Brunekreef B, Cyrys J, de Faire U, et al. Long-term effects of elemental composition of particulate matter on inflammatory blood markers in European cohorts. Environment international. 2015;82:76-84.

36. Wu CF, Li YR, Kuo IC, Hsu SC, Lin LY, Su TC. Investigating the association of cardiovascular effects with personal exposure to particle components and sources. The Science of the total environment. 2012;431:176-82.

37. de Hoogh K, Wang M, Adam M, Badaloni C, Beelen R, Birk M, et al. Development of land use regression models for particle composition in twenty study areas in Europe. Environmental science \& technology. 2013;47(11):5778-86. 
38. Yu CH, Fan ZH, Meng Q, Zhu X, Korn L, Bonanno LJ. Spatial/temporal variations of elemental carbon, organic carbon, and trace elements in PM10 and the impact of land-use patterns on community air pollution in Paterson, NJ. J Air Waste Manag Assoc. 2011;61(6):673-88.

39. Akintoye E, Shi L, Obaitan I, Olusunmade M, Wang Y, Newman JD, et al. Association between fine particulate matter exposure and subclinical atherosclerosis: A meta-analysis. European journal of preventive cardiology. 2016;23(6):602-12.

40. Fuller $\mathrm{CH}$, Feeser KR, Sarnat JA, O'Neill MS. Air pollution, cardiovascular endpoints and susceptibility by stress and material resources: a systematic review of the evidence. Environmental health : a global access science source. 2017;16(1):58.

41. Chi GC, Hajat A, Bird CE, Cullen MR, Griffin BA, Miller KA, et al. Individual and Neighborhood Socioeconomic Status and the Association between Air Pollution and Cardiovascular Disease. Environmental health perspectives. 2016;124(12):1840-7.

42. Dragano N, Hoffmann B, Moebus S, Möhlenkamp S, Stang A, Verde PE, et al. Traffic exposure and subclinical cardiovascular disease: is the association modified by socioeconomic characteristics of individuals and neighbourhoods? Results from a multilevel study in an urban region. Occup Environ Med. 2009;66(9):628-35.

43. Diez Roux AV, Borrell LN, Haan M, Jackson SA, Schultz R. Neighbourhood environments and mortality in an elderly cohort: results from the cardiovascular health study. J Epidemiol Community Health. 2004;58(11):917-23.

44. Chen SY, Chu DC, Lee JH, Yang YR, Chan CC. Traffic-related air pollution associated with chronic kidney disease among elderly residents in Taipei City. Environmental pollution (Barking, Essex : 1987). 2018;234:838-45.

45. Mehta AJ, Zanobetti A, Bind MA, Kloog I, Koutrakis P, Sparrow D, et al. Long-Term Exposure to Ambient Fine Particulate Matter and Renal Function in Older Men: The Veterans Administration Normative Aging Study. Environmental health perspectives. 2016;124(9):1353-60.

46. Cheng $\mathrm{FY}, \mathrm{Hsu} \mathrm{CH}$. Long-term variations in $\mathrm{PM}(2.5)$ concentrations under changing meteorological conditions in Taiwan. Sci Rep. 2019;9(1):6635.

47. Lin CY, Chen PC, Lo SC, Torng PL, Sung FC, Su TC. The association of carotid intima-media thickness with serum Level of perfluorinated chemicals and endothelium-platelet microparticles in adolescents and young adults. Environment international. 2016;94:292-9.

48. Su TC, Hwang JS, Torng PL, Wu C, Lin CY, Sung FC. Phthalate exposure increases subclinical atherosclerosis in young population. Environmental pollution (Barking, Essex : 1987). 2019;250:58693.

\section{Tables}

Table 1 The distribution of study subjects and CIMT measurements stratified by individual characteristics 


\begin{tabular}{|c|c|c|c|c|}
\hline & $n(\%)$ & LCCA $(\mathrm{mm})$ & $\mathrm{RCCA}(\mathrm{mm})$ & $\mathrm{CCA}(\mathrm{mm})$ \\
\hline \multicolumn{5}{|l|}{ Sex } \\
\hline Male & $313(39.7)$ & $0.44 \pm 0.06$ & $0.46 \pm 0.06$ & $0.46 \pm 0.06$ \\
\hline Female & $476(60.3)$ & $0.46 \pm 0.07$ & $0.44 \pm 0.05$ & $0.44 \pm 0.05$ \\
\hline \multicolumn{5}{|l|}{ Age, year } \\
\hline$<18$ & $104(13.2)$ & $0.45 \pm 0.06$ & $0.44 \pm 0.05$ & $0.44 \pm 0.05$ \\
\hline$\geq 18$ & $685(86.8)$ & $0.44 \pm 0.06$ & $0.45 \pm 0.06$ & $0.45 \pm 0.06$ \\
\hline \multicolumn{5}{|c|}{ Current smoking } \\
\hline No & $684(86.7)$ & $0.44 \pm 0.06$ & $0.45 \pm 0.06$ & $0.45 \pm 0.05$ \\
\hline Yes & $105(13.3)$ & $0.46 \pm 0.07$ & $0.45 \pm 0.06$ & $0.46 \pm 0.06$ \\
\hline \multicolumn{5}{|c|}{ Household income (NTD/month) } \\
\hline$<50,000$ & $293(37.1)$ & $0.45 \pm 0.07$ & $0.45 \pm 0.06$ & $0.45 \pm 0.06$ \\
\hline$\geq 50,000$ & $496(62.9)$ & $0.45 \pm 0.06$ & $0.44 \pm 0.05$ & $0.45 \pm 0.05$ \\
\hline \multicolumn{5}{|c|}{ Overweight (BMI $\geq 25$ kg/m²) } \\
\hline No & $653(82.8)$ & $0.44 \pm 0.05$ & $0.44 \pm 0.05$ & $0.44 \pm 0.05$ \\
\hline Yes & $136(17.2)$ & $0.47 \pm 0.08$ & $0.47 \pm 0.07$ & $0.47 \pm 0.07$ \\
\hline \multicolumn{5}{|c|}{ Hypertension ${ }^{a}$} \\
\hline No & $746(94.5)$ & $0.44 \pm 0.06$ & $0.45 \pm 0.05$ & $0.45 \pm 0.05$ \\
\hline yes & $43(5.5)$ & $0.49 \pm 0.09$ & $0.48 \pm 0.09$ & $0.49 \pm 0.08$ \\
\hline \multicolumn{5}{|c|}{ Hyperglycemia ( $\geq 100 \mathrm{mg} / \mathrm{dL})$} \\
\hline No & $607(76.9)$ & $0.44 \pm 0.06$ & $0.45 \pm 0.06$ & $0.45 \pm 0.05$ \\
\hline yes & $182(23.1)$ & $0.50 \pm 0.12$ & $0.48 \pm 0.07$ & $0.46 \pm 0.07$ \\
\hline \multicolumn{5}{|c|}{ Hypercholesterolemia ( $\geq 200$ mg/dL) } \\
\hline No & $622(78.8)$ & $0.44 \pm 0.06$ & $0.44 \pm 0.05$ & $0.45 \pm 0.05$ \\
\hline Yes & $167(21.2)$ & $0.46 \pm 0.08$ & $0.46 \pm 0.07$ & $0.46 \pm 0.07$ \\
\hline
\end{tabular}

Data are presented by $n(\%)$ or mean \pm SD.

${ }^{a}$ Defined as either had self-reported physician-diagnosed hypertension and used anti-hypertensive medication or had measured blood pressure (BP) values $\geq 140 \mathrm{mmHg}$ for systolic BP or $\geq 90 \mathrm{mmHg}$ for diastolic BP. 
Table 2 Estimated one-year exposure concentrations of $\mathrm{PM}_{2.5}$ and its elemental constituents for study subjects

\begin{tabular}{|cclll|}
\hline Air Pollutants & No. & Mean \pm SD & IQR & Range \\
\hline $\mathrm{PM}_{2.5}\left(\mu \mathrm{g} / \mathrm{m}^{3}\right)$ & 779 & $24.9 \pm 5.0$ & 4.5 & $15.6-58.0$ \\
\hline $\mathrm{Si}\left(\mathrm{ng} / \mathrm{m}^{3}\right)$ & 779 & $424.2 \pm 55.5$ & 77.6 & $249.9-542.6$ \\
\hline $\mathrm{S}\left(\mathrm{ng} / \mathrm{m}^{3}\right)$ & 779 & $2180.6 \pm 185.1$ & 116.6 & $1769.3-3495.6$ \\
\hline $\mathrm{Ti}\left(\mathrm{ng} / \mathrm{m}^{3}\right)$ & 779 & $19.5 \pm 3.1$ & 4.0 & $8.8-25.3$ \\
\hline $\mathrm{Mn}\left(\mathrm{ng} / \mathrm{m}^{3}\right)$ & 756 & $16.1 \pm 6.1$ & 2.0 & $13.3-99.2$ \\
\hline $\mathrm{Fe}\left(\mathrm{ng} / \mathrm{m}^{3}\right)$ & 779 & $244.8 \pm 33.7$ & 34.7 & $172.9-464.4$ \\
\hline $\mathrm{Ni}\left(\mathrm{ng} / \mathrm{m}^{3}\right)$ & 779 & $6.5 \pm 1.5$ & 2.1 & $3.5-11.2$ \\
\hline $\mathrm{Cu}\left(\mathrm{ng} / \mathrm{m}^{3}\right)$ & 779 & $10.1 \pm 4.0$ & 3.6 & $2.2-36.4$ \\
\hline $\mathrm{Zn}\left(\mathrm{ng} / \mathrm{m}^{3}\right)$ & 755 & $86.7 \pm 19.0$ & 20.7 & $42.8-197.2$ \\
\hline
\end{tabular}

Table 3 Percent difference in CIMT values at different segments for an IQR increase in PM 2.5 and its elemental constituents 


\begin{tabular}{|c|c|c|c|c|c|}
\hline \multirow[t]{2}{*}{ Exposures (IQR) } & \multirow[t]{2}{*}{ Models } & \multirow{2}{*}{$\begin{array}{l}\text { No. of } \\
\text { subjects }\end{array}$} & \multicolumn{3}{|c|}{ Percent difference $(95 \% \mathrm{Cl})$ in CIMT } \\
\hline & & & LCCA & RCCA & Combined CCA \\
\hline \multirow{2}{*}{$\begin{array}{l}\mathrm{PM}_{2.5}(4.5 \\
\left.\mu \mathrm{g} / \mathrm{m}^{3}\right)\end{array}$} & Main & 779 & $\begin{array}{l}0.84(-0.03 \\
1.72)\end{array}$ & $\begin{array}{l}0.83(0.03 \\
1.62)\end{array}$ & $\begin{array}{l}0.77(0.05 \\
1.50)\end{array}$ \\
\hline & Extended & & $\begin{array}{l}0.84(-0.04, \\
1.72)\end{array}$ & $\begin{array}{l}0.76(-0.04 \\
1.56)\end{array}$ & $\begin{array}{l}0.75(0.02 \\
1.48)\end{array}$ \\
\hline \multirow[t]{2}{*}{$\mathrm{Si}\left(77.6 \mathrm{ng} / \mathrm{m}^{3}\right)$} & Main & 779 & $\begin{array}{l}1.18(-0.18 \\
2.55)\end{array}$ & $\begin{array}{l}0.15(-1.09 \\
1.38)\end{array}$ & $\begin{array}{l}0.35(-0.78 \\
1.48)\end{array}$ \\
\hline & Extended & & $\begin{array}{l}1.11(-0.26 \\
2.47)\end{array}$ & $\begin{array}{l}0.16(-1.09 \\
1.40)\end{array}$ & $\begin{array}{l}0.32(-0.82 \\
1.45)\end{array}$ \\
\hline \multirow[t]{2}{*}{$\mathrm{S}\left(116.6 \mathrm{ng} / \mathrm{m}^{3}\right)$} & Main & 779 & $\begin{array}{l}0.43(-0.18 \\
1.04)\end{array}$ & $\begin{array}{l}0.45(-0.10 \\
1.01)\end{array}$ & $\begin{array}{l}0.42(-0.08 \\
0.93)\end{array}$ \\
\hline & Extended & & $\begin{array}{l}0.42(-0.19 \\
1.04)\end{array}$ & $\begin{array}{l}0.42(-0.14 \\
0.98)\end{array}$ & $\begin{array}{l}0.40(-0.11 \\
0.91)\end{array}$ \\
\hline \multirow[t]{2}{*}{$\mathrm{Ti}\left(4.0 \mathrm{ng} / \mathrm{m}^{3}\right)$} & Main & 779 & $\begin{array}{l}0.46(-0.77 \\
1.68)\end{array}$ & $\begin{array}{l}-0.19(-1.29, \\
0.92)\end{array}$ & $\begin{array}{l}-0.05(-1.06 \\
0.97)\end{array}$ \\
\hline & Extended & & $\begin{array}{l}0.42(-0.82 \\
1.65)\end{array}$ & $\begin{array}{l}-0.16(-1.28, \\
0.97)\end{array}$ & $\begin{array}{l}-0.05(-1.07 \\
0.97)\end{array}$ \\
\hline \multirow[t]{2}{*}{$\operatorname{Mn}\left(2.0 \mathrm{ng} / \mathrm{m}^{3}\right)$} & Main & 756 & $\begin{array}{l}0.20(-0.12, \\
0.53)\end{array}$ & $\begin{array}{l}0.31(0.01 \\
0.60)\end{array}$ & $\begin{array}{l}0.27(0.00 \\
0.53)\end{array}$ \\
\hline & Extended & & $\begin{array}{l}0.22(-0.10 \\
0.55)\end{array}$ & $\begin{array}{l}0.30(0.01 \\
0.60)\end{array}$ & $\begin{array}{l}0.27(0.00 \\
0.54)\end{array}$ \\
\hline \multirow[t]{2}{*}{$\mathrm{Fe}\left(34.7 \mathrm{ng} / \mathrm{m}^{3}\right)$} & Main & 779 & $\begin{array}{l}1.07(0.07 \\
2.06)\end{array}$ & $\begin{array}{l}0.77(-0.13 \\
1.67)\end{array}$ & $\begin{array}{l}0.83(0.01 \\
1.65)\end{array}$ \\
\hline & Extended & & $\begin{array}{l}1.05(0.06 \\
2.05)\end{array}$ & $\begin{array}{l}0.70(-0.21 \\
1.61)\end{array}$ & $\begin{array}{l}0.79(-0.04 \\
1.62)\end{array}$ \\
\hline \multirow[t]{2}{*}{$\mathrm{Ni}\left(2.1 \mathrm{ng} / \mathrm{m}^{3}\right)$} & Main & 779 & $\begin{array}{l}0.15(-1.25 \\
1.55)\end{array}$ & $\begin{array}{l}0.18(-1.09 \\
1.45)\end{array}$ & $\begin{array}{l}0.20(-0.95 \\
1.36)\end{array}$ \\
\hline & Extended & & $\begin{array}{l}0.13(-1.28 \\
1.54)\end{array}$ & $\begin{array}{l}0.18(-1.10 \\
1.46)\end{array}$ & $\begin{array}{l}0.23(-0.95 \\
1.40)\end{array}$ \\
\hline \multirow[t]{2}{*}{$\mathrm{Cu}\left(3.6 \mathrm{ng} / \mathrm{m}^{3}\right)$} & Main & 779 & $\begin{array}{l}0.63(-0.24 \\
1.50)\end{array}$ & $\begin{array}{l}0.62(-0.16 \\
1.41)\end{array}$ & $\begin{array}{l}0.60(-0.11 \\
1.32)\end{array}$ \\
\hline & Extended & & $\begin{array}{l}0.62(-0.26 \\
1.49)\end{array}$ & $\begin{array}{l}0.55(-0.24 \\
1.34)\end{array}$ & $\begin{array}{l}0.56(-0.16 \\
1.28)\end{array}$ \\
\hline \multirow[t]{2}{*}{$\mathrm{Zn}\left(20.7 \mathrm{ng} / \mathrm{m}^{3}\right)$} & Main & 755 & $\begin{array}{l}1.37(0.31 \\
2.43)\end{array}$ & $\begin{array}{l}1.13(0.17 \\
2.10)\end{array}$ & $\begin{array}{l}1.22(0.35 \\
2.10)\end{array}$ \\
\hline & Extended & & $\begin{array}{l}1.38(0.31 \\
2.45)\end{array}$ & $\begin{array}{l}1.08(0.10 \\
2.05)\end{array}$ & $\begin{array}{l}1.19(0.30 \\
2.07)\end{array}$ \\
\hline
\end{tabular}


The main models calculated by multiple liner models, adjusted for age, sex, household income, smoking status, body mass index, systolic blood pressure, fasting glucose, and cholesterol. The extended models were further adjusted for urinary cotinine levels in addition to covariates in the main models.

\section{Figures}

(A)

(C)
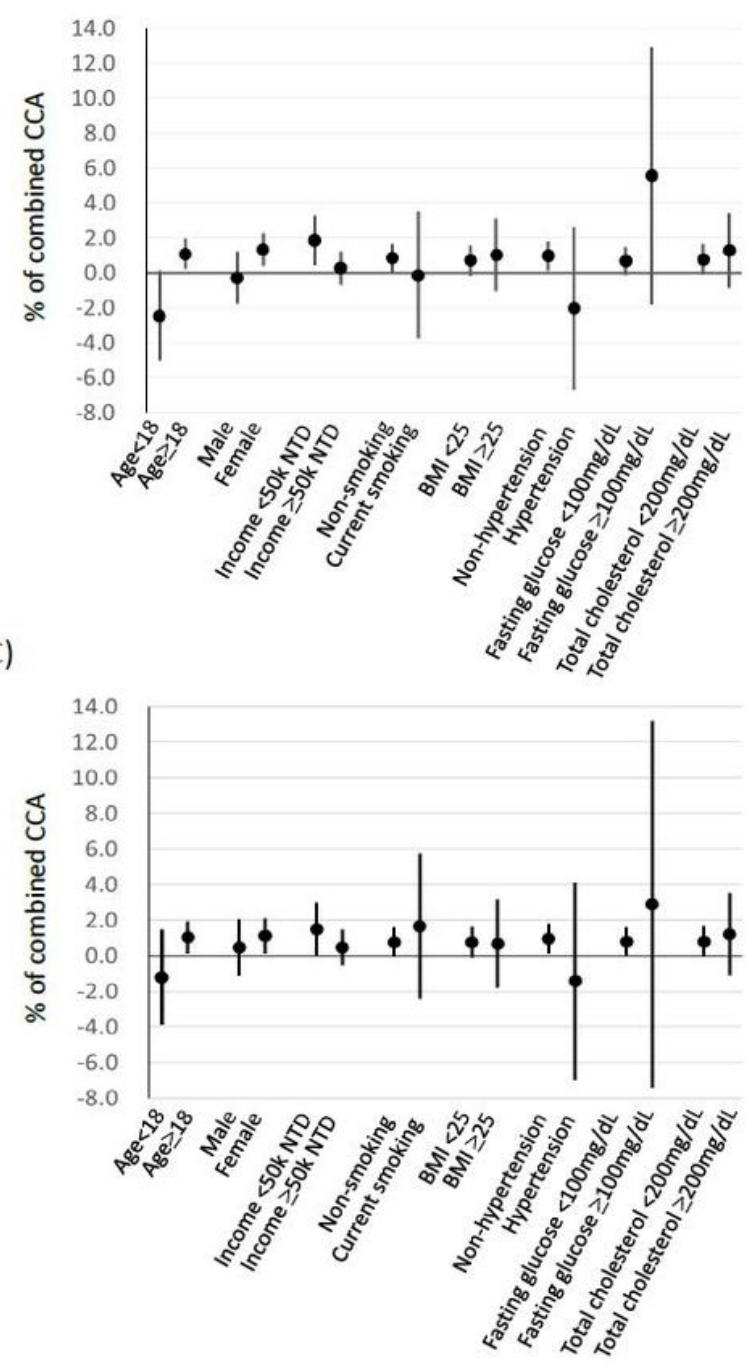

(B)
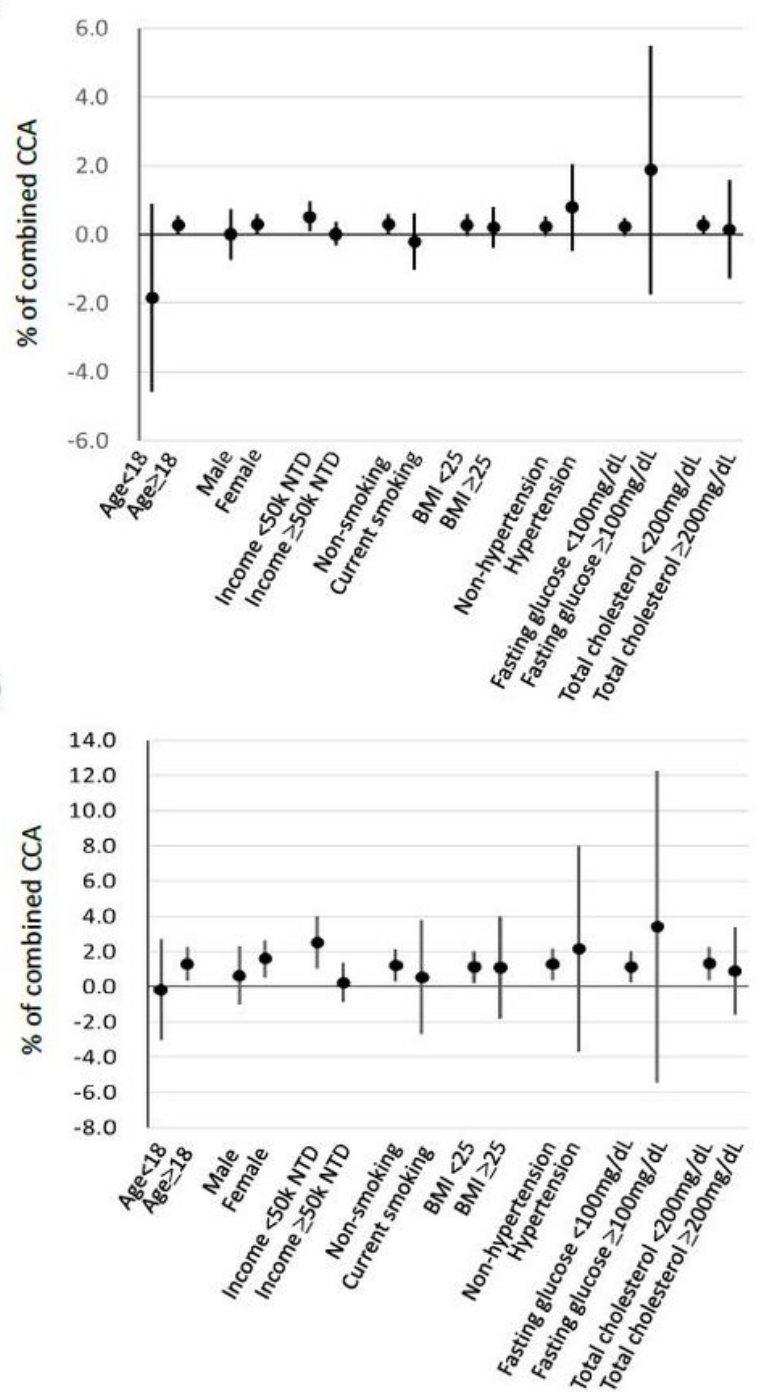

Figure 1

Percent changes (95\% Cls) of combined CCA values in association with an increment of (A) $4.5 \mu \mathrm{g} / \mathrm{m} 3$ for PM2.5; (B) $2.0 \mathrm{ng} / \mathrm{m} 3$ for Mn; (C) $34.7 \mathrm{ng} / \mathrm{m} 3$ for Fe; and (D) $20.7 \mathrm{ng} / \mathrm{m} 3$ for Zn stratified by age (<18 vs. $\geq 18$ years), sex, household income (<NTD 50,000/month vs. $\geq$ NTD 50,000/month), smoking, overweightness (BMl $<25 \mathrm{vs}$. BMI $\geq 25 \mathrm{~kg} / \mathrm{m} 2$ ), hypertension, hyperglycemia (fasting glucose $<100 \mathrm{mg} / \mathrm{dL}$ vs. $\geq 100 \mathrm{mg} / \mathrm{dL}$ ), or hypercholesterolemia (total cholesterol $<200 \mathrm{mg} / \mathrm{dL}$ vs. $\geq 200 \mathrm{mg} / \mathrm{dL}$ ). The estimates were calculated by linear regressions, adjusted for age, sex, household income, smoking, body mass index, and individual comorbid conditions other than analyzed stratum. 


\section{Supplementary Files}

This is a list of supplementary files associated with this preprint. Click to download.

- Additionalfile1.docx

- Additionalfile2.docx

- Additionalfile3.docx 